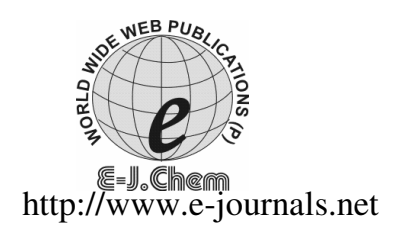

ISSN: 0973-4945; CODEN ECJHAO

E-Journal of Chemistry

2011, 8(3), 1006-1013

\title{
Kinetic Studies of Reduction of Tris-(1,1,1,5,5,5-hexafluoroacetylacetonato) ruthenium(III) in Methanol, Ethanol and Propanol
}

\author{
EZEKIEL DIXON DIKIO
}

Department of Chemistry, Vaal University of Technology

P. O. Box X021, Vanderbijlpark 1900, Republic of South Africa

ezekield@vut.ac.za

Received 2 August 2010; Revised 10 November 2010; Accepted 20 November 2010

\begin{abstract}
The complex tris-(1,1,1,5,5,5-hexafluoroacetylacetonato-) ruthenium(III), hereafter referred to as $\mathrm{Ru}(\mathrm{hfacac})_{3}$, has been synthesized. Ultraviolet and visible spectroscopic measurements of the complex in ethanol revealed three prominent absorption bands at 287,374 and $525 \mathrm{~nm}$ with molar absorptivity coefficients of $4.113,3.885$ and 3.59 respectively. Magnetic susceptibility measurements between 78 and $296 \mathrm{~K}$ revealed the complex to assume a low spin configuration of $e^{0} t_{2 g}^{5}$ and an oxidation state of +3 as inferred from a value of 1.92 Bohr magneton. Kinetic investigation of the reduction of the complex in methanol, ethanol and propanol indicate the reduction to proceed in the order methanol $>$ ethanol $>$ propanol. The energies of activation of the reduction in methanol and ethanol were found to be 85.4 and $108 \mathrm{~kJ} / \mathrm{mol}$ respectively.
\end{abstract}

Keywords: Ruthenium(III), Ruthenium(II), Kinetics, Hexafluoroacetylacetone, Ru(hfacac) 3

\section{Introduction}

The reactions of metals with $\beta$-diketones have been known for well over a century ${ }^{1}$. During this period, several researches have been conducted the world over on the synthesis ${ }^{2}$, catalytic activity ${ }^{3-5}$ mass spectroscopy ${ }^{6}$, gas chromatography ${ }^{7}, x_{-}$ray $^{8}$ solvent dynamics ${ }^{9}$ and in a wide range of subjects ${ }^{10}$ concerning ruthenium $\beta$-diketonates ${ }^{4}$. Complexes of fluorinated $\beta$-diketones have been investigated ${ }^{11-13}$ for its solvent extraction capabilities and as NMR shift reagents. Most studies have been carried out in solvents such as acetonitrile while a few have been in alcohols.

Ruthenium(II) and ruthenium(III) form low spin $d^{5}$ and $d^{6}$ complexes with numerous derivatives of the ligand acetylacetone ${ }^{14}$. Metal 1,3-diketone systems behave as sensitive heterocycles possessing at least some aromatic character. Holm and cotton ${ }^{15}$ have expressed doubt in such aromaticity but collman et $a l^{16}$ and other workers have recognized their quasi- 
aromatic character and have reported electrophilic substitution reactions in these systems. $\beta$-Diketones have the property of forming stable anions as a result of enolization followed by ionization. The ketoenolate ions form very stable chelate complexes with a variety of metal ions ${ }^{11}$.

The 1,1,1,5,5,5-hexafluoro-2,4-pentane dione complex of ruthenium(III) has a characteristically strong oxidizing property compared to other $\beta$-diketones. Studies of fluorinated $\beta$-diketone complexes of ruthenium(III) show these compounds to undergo reduction in alcoholic solutions of alkali hydroxides ${ }^{12-13}$. These studies were conducted with compounds of ruthenium $\beta$-diketonates such as tris-(1,1,1-trifluoro-2,4-pentanedionato-) ruthenium(III), 4,4,4-trifluoro-1-(phenylbutane-1,3-dione, 4,4,4-trifluoro-1-(2-naphthyl)butane-1,3-dione and 4,4,4-trifluoro-1-(2-thienyl)-butane-1,3-dione ${ }^{12}$.

A survey of available literature ${ }^{17-20}$ indicate that no studies have been undertaken as regards the action of alcoholic alkali hydroxide solutions on the hexafluoroacetylacetone (hfacac) of ruthenium(III).

This complex is not very stable probably because of the large number of fluorine atoms it possess and also because it is difficult to synthesize. The objective of this work was to measure the rate of reduction of tris-(1,1,1,5,5,5-hexafluoroacetylacetonato) ruthenium(III) in methanol, ethanol and propanol as well in the presence of alcoholic alkali hydroxide solutions.

\section{Experimental}

Analytical grade reagents were used throughout this work. 1,1,1,5,5,5-Hexafluoroacetylacetone (hfacac) was purchased from Eastman Kodak Company. Ru(hfacac) 3 was prepared and purified according to ruthenium blue ${ }^{2}$ method with modifications as described in the synthesis procedure. Magnetic susceptibility measurements were carried out on a magnetic susceptibility balance (Sherwood Scientific) at room temperature by Gouy's method. Ultraviolet-visible spectroscopy was measured on a Cary 50 spectrophotometer.

\section{Synthesis}

0.0025 moles of ruthenium(III) chloride $\left(\mathrm{RuCl}_{3} \cdot 3 \mathrm{H}_{2} \mathrm{O}\right)$ were weighed and dissolved in $10 \mathrm{~mL}$ of $3 \mathrm{M}$ hydrochloric acid. The solution of ruthenium chloride in $\mathrm{HC} \ell$ was then evaporated to dryness indirectly on a heating mantle at $80{ }^{\circ} \mathrm{C}$. When completely dried, a few drops of ethanol was added to dissolve the solid material and again evaporated to dryness. Solid materials obtained at the end of the evaporation process were then dissolved in $50 \mathrm{~mL}$ of ethanol in a $250 \mathrm{~mL}$ round bottom flask giving a greenish solution. 0.0031 moles of the ligand hexafluoroacetylacetone (hfacac) was then added. The mixture was then warmed under reflux for about one hour. During reflux, 0.0025 moles of potassium hydrogen carbonate $\left(\mathrm{KHCO}_{3}\right)$ was added. The refluxing was then continued for $24 \mathrm{~h}$. Another portion of 0.000125 moles of potassium hydrogen carbonate was again added with $10 \mathrm{~mL}$ of ethanol. Heating was then continued for a further 48 hours. At the end of the synthesis, the reaction mixture was filtered on a sintered glass funnel No 3. The filtrate obtained was evaporated to dryness with $n$-pentane added to hasten evaporation. An oily liquid resulted which was washed with chloroform and filtered at the pump. Dark brown crystals were obtained which weighed $0.43 \mathrm{~g}$. The crystals were again washed with double distilled water at the pump and evaporated to dryness. Reddish crystals obtained were purified by sublimation. A yield of $48.8 \mathrm{mg}$ of ruthenium(III) hexafluoroacetylacetone $\mathrm{Ru}(\mathrm{hfacac})_{3}$ was obtained. Melting point of the crystals was found to be $98-99{ }^{\circ} \mathrm{C}$ which is in agreement with literature $^{12}$. 


\section{Kinetic measurement}

Kinetic measurement of the rate of reduction of $\mathrm{Ru}(\mathrm{hfacac})_{3}$ in methanol, ethanol and propanol at various temperatures was followed spectrophotometrically with a Cary 50 spectrophotometer. These measurements were based on the absorbance wavelength due to ruthenium(III) at $374 \mathrm{~nm}$. A $0.1 \mathrm{M}$ solution of potassium hydroxide was prepared in ethanol and standardized against a standard $0.1 \mathrm{M}$ potassium hydrogen phthalate solution. A $1.4 \times 10^{-4}$ $\mathrm{M}$ solution of $\mathrm{Ru}(\mathrm{hfacac})_{3}$ was reacted with $0.1 \mathrm{M}$ solution potassium hydroxide. The two solutions were mixed and quickly transferred to a $1 \mathrm{~cm}$ quartz cell in a thermostated compartment of the UV Vis spectrometer. The UV Vis absorption spectrum 300-800 $\mathrm{nm}$ was then scanned at specific time intervals. Maintenance of isosbestic point throughout the entire reaction was an indication of a simple reaction.

Rate measurements for the reduction of $\mathrm{Ru}(\mathrm{hfacac})_{3}$ in the alcohols were made under pseudo-first order conditions with the alcohol in excess. The reaction equation is as follows:

$$
2 \mathrm{Ru}(\text { hfacac })_{3}+\mathrm{ROH} \rightarrow 2 \mathrm{Ru}(\text { hfacac })^{-}{ }_{3}+\mathrm{R}^{\prime} \mathrm{CHO}+2 \mathrm{H}^{+}
$$

Where, R' $=\mathrm{H}, \mathrm{CH}_{3}, \mathrm{C}_{2} \mathrm{H}_{5}, \mathrm{C}_{3} \mathrm{H}_{7}$

$$
-\frac{d\left[R u(h f a c a c)_{3}\right]}{d t}=k_{o}[R O H]\left[R u(h f a c a c)_{3}\right]^{2}
$$

Where, $k_{o}$ is the observed rate constant.

$$
-\frac{d\left[R u(h f a c a c)_{3}\right]}{d t}=k_{\text {exp } t}\left[R u(h f a c a c)_{3}\right]^{2}
$$

Where, $k_{\text {expt }}=k_{o}[\mathrm{ROH}]$

\section{Results and Discussion}

Spectral measurements of the complex in chloroform and ethanol in the ultraviolet and visible region gave three prominent absorption bands at 287,374 and $525 \mathrm{~nm}$. The band at $287 \mathrm{~nm}$ has a molar absorptivity coefficient of $13000 \mathrm{~L} / \mathrm{mol} \mathrm{cm}$. The band at $374 \mathrm{~nm}$ and $525 \mathrm{~nm}$ have molar absorptivity coefficient of 7667 and $3889 \mathrm{~L} / \mathrm{mol} \mathrm{cm}$ respectively. This band at $287 \mathrm{~nm}$ is found in all $\beta$-diketones and their complexes for which upon chelation with a metal ion may be shifted either to longer or shorter wavelength with respect to the ligand. Barnum ${ }^{20}$ attributed these among others to the effect of metal- ligand $\pi$-interactions in trivalent transition metal complexes, for which ruthenium is in the trivalent state. The observed band at $287 \mathrm{~nm}$ has been assigned as a $\pi-\pi$ transition originating from the ligand hexafluoroacetylacetone (Hhfacac), holm and cotton, and Barnum ${ }^{15,20}$ and other researchers have stated that the origin of these bands are not known since they also occur in iron(III) $\beta$-diketones. Despite the controversy surrounding these bands, they could be said to be charge transfer transitions between the metal and ligand and metal. Electronic configuration of ruthenium(III) is known to be $d^{5}$ and low spinned with an unfilled orbital on the $4 d$ orbital in the $t_{2 g}$ degenerate level, it is possible for a transition from the $\pi$ - orbital of the ligand to the metal to occur. However, for a low spinned ruthenium(II) with an orbital electron distribution in which the $t_{2 g}$ level is filled, it cannot accept any electron from the ligand to the $t_{2 g}$ level rather, it would most likely produce a transition from metal to ligand. Since the splitting energy of the octahedral field is large, transition to the $e_{g}$ level is not possible.

Therefore, the band at $374 \mathrm{~nm}$ is $\pi-t_{2 g}$ transition in ruthenium(III) while the band which occurs at $525 \mathrm{~nm}$ is a $t_{2 g}-\pi^{*}$ transition for ruthenium(II). Again, in the region under discussion, the existence of $d-d$ transition in metal ion cannot be excluded. If they do occur, they are overlapped by the intensity of the charge transfer transition. 
The effective magnetic moment $\mu_{\text {eff }}$ for ruthenium(III) from magnetic susceptibility measurement of the synthesized complex using Gouy method was found to be $\mu_{\text {eff }}=1.92 \mathrm{BM}$. This approximates to the presence of one unpaired electron since the magnetic moment of a single unpaired electron has a value of 1.73 BM.

Kinetic measurements were carried out at room temperature, approximately $25^{\circ} \mathrm{C}$, in alcohols. The reaction kinetics was monitored spectroscopically at $\lambda_{\max } 374 \mathrm{~nm}$ which decreases due to reduction of ruthenium(III) or at $525 \mathrm{~nm}$ which increases due to oxidation of ruthenium(II).

The reduction reaction in methanol, ethanol and propanol were initiated by the dissolution of the $\mathrm{Ru}(\mathrm{hfacac})_{3}$ in the respective alcohols. Ru(hfacac $)_{3}$ is not stable in the lower alcohols, instability being attributable to the large number of fluorine atoms. Studies by a number of researchers indicate that the substitution of methyl $\left(-\mathrm{CH}_{3}\right)$ influences complex stability, increases volatility and decreases thermal stability ${ }^{5}$.

In methanol, the reduction reaction was complete within one hour which indicates a single set of reactants producing a single set of products as may be deduced from the single isosbestic point produced at $437 \mathrm{~nm}$ (Figure 1). The rate of the reaction at $25,30 \& 35^{\circ} \mathrm{C}$ produces straight lines when plotted as pseudo-first order kinetic reaction (Figure 2). Rate constants for the reaction at various temperatures are tabulated in Table 1.

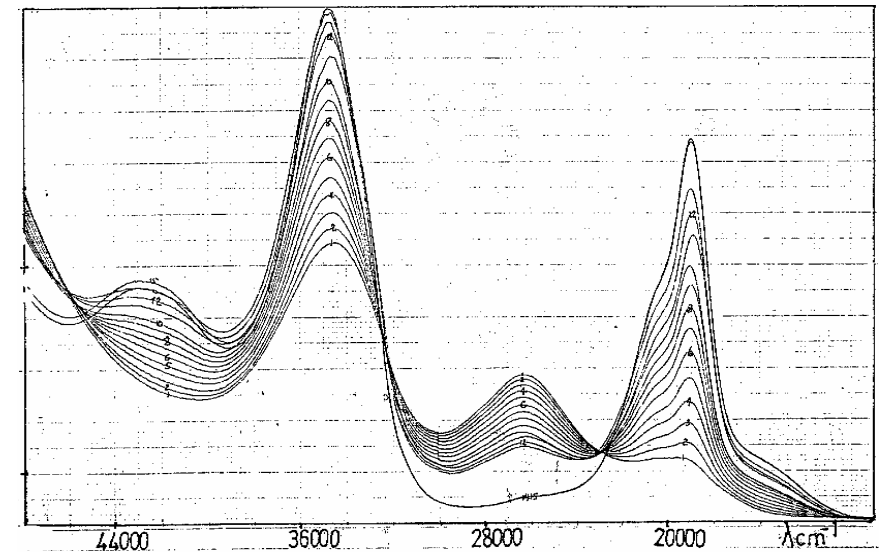

Figure 1. Absorbance measurement of $\mathrm{Ru}(\mathrm{hfacac})_{3}$ in methanol

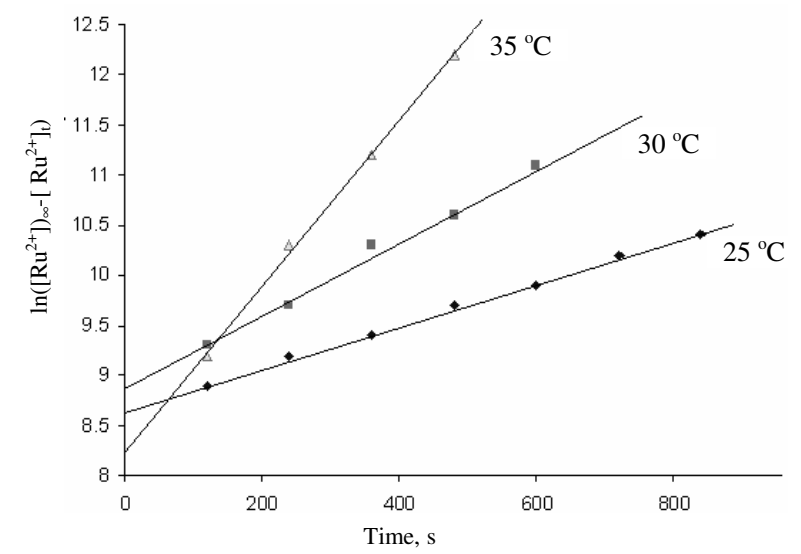

Figure 2. Rate measurement of $\mathrm{Ru}(\mathrm{hfacac})_{3}$ in methanolic $\mathrm{KOH}$ solution at 25,30 and $35^{\circ} \mathrm{C}$ 
Table 1. Rate constants and half life for kinetic measurement in methanol

\begin{tabular}{cccc}
\hline Temperature, $\mathrm{K}$ & $\mathrm{k} /$ mole $\times 10^{4}$ & $\ln \mathrm{k}$ & $\mathrm{t}_{1 / 2}(\mathrm{~s})$ \\
\hline 288 & 0.521 & -9.86 & 1300.8 \\
298 & 1.23 & -9.00 & 5620 \\
303 & 2.95 & -8.13 & 2349.65 \\
308 & 5.38 & -7.53 & 1287.58 \\
\hline
\end{tabular}

In ethanol, the reduction reaction process was complete in less than four hours at $25{ }^{\circ} \mathrm{C}$. This reaction also produces a well defined isosbestic point at $433 \mathrm{~nm}$ which indicates a single set of reactants giving rise to a single set of products (Figure 3 ). The rate of the reaction at $25,30 \& 35{ }^{\circ} \mathrm{C}$ produces straight lines when plotted as a pseudo-first order kinetic reaction (Figure 4). Rate constants for the reaction at various temperatures are tabulated in Table 2.

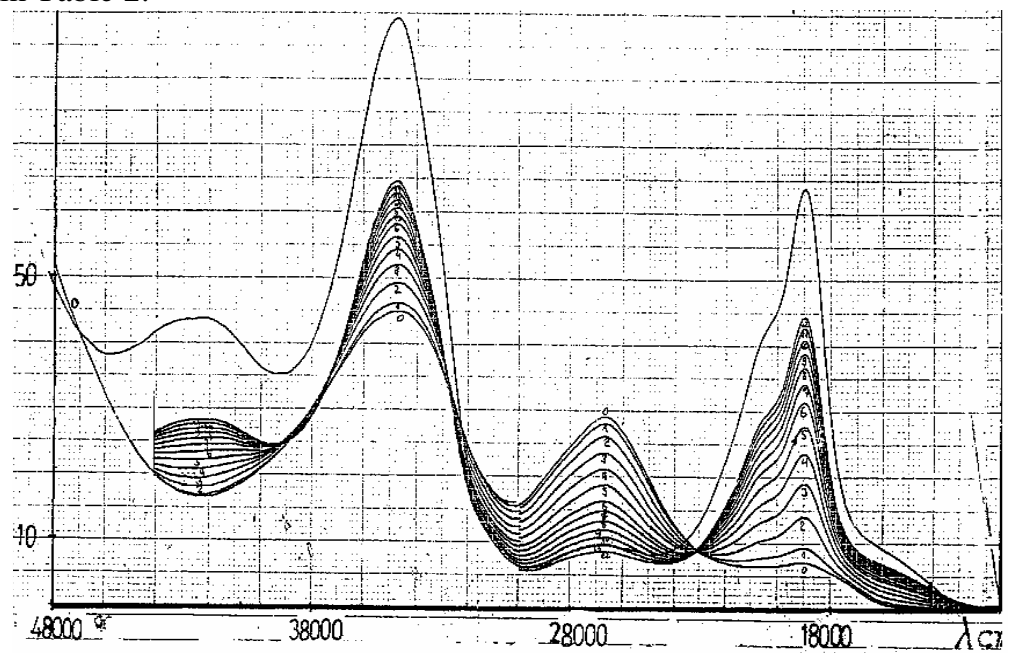

Figure 3. Absorbance measurement of $\mathrm{Ru}(\mathrm{hfacac})_{3}$ in ethanol

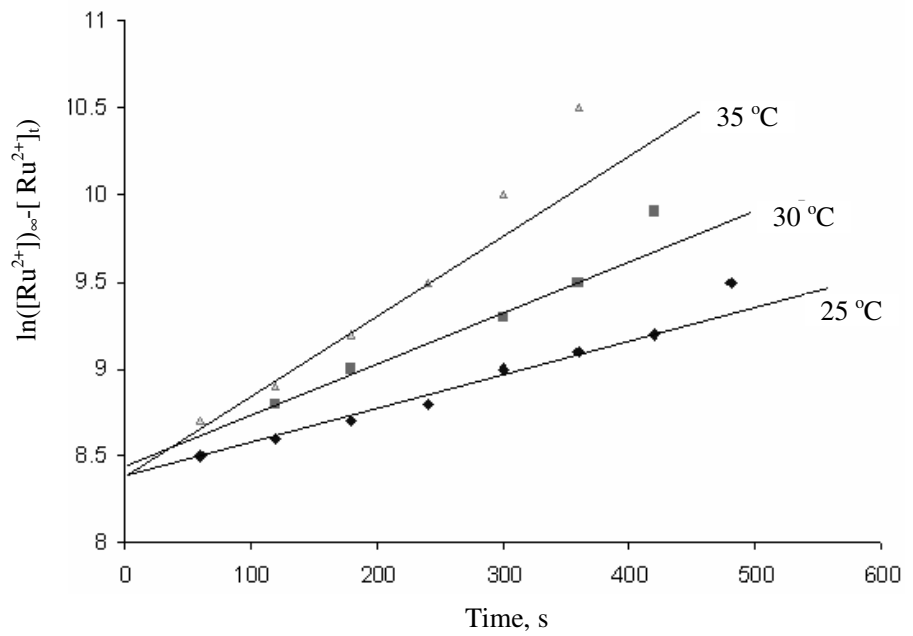

Figure 4. Rate measurement of $\mathrm{Ru}(\mathrm{hfacac})_{3}$ in ethanolic $\mathrm{KOH}$ solution at 25,30 and $35^{\circ} \mathrm{C}$ 
Table 2. Rate constants and half life for kinetic measurement in ethanol

\begin{tabular}{cccc}
\hline Temperature, $\mathrm{K}$ & $\mathrm{k} \mathrm{mole} / \mathrm{s} \times 10^{5}$ & $\ln \mathrm{k}$ & $\mathrm{t}_{1 / 2}(\mathrm{~s}) \times 10^{4}$ \\
\hline 298 & 3.07 & -10.39 & 2.26 \\
303 & 5.55 & -9.80 & 1.25 \\
308 & 9.67 & -9.24 & \\
\hline
\end{tabular}

In propanol however, the reduction reaction process does not go directly to completion. An equilibrium is established somewhere in the system with the production of a diffused isosbestic point between 417 and $434 \mathrm{~nm}$ (Figure 5). The rate of the reaction at $30 \& 40{ }^{\circ} \mathrm{C}$ produces straight lines when plotted as a pseudo-first order kinetic reaction (Figure 6). Rate constants for the reaction at various temperatures are tabulated in Table 3.

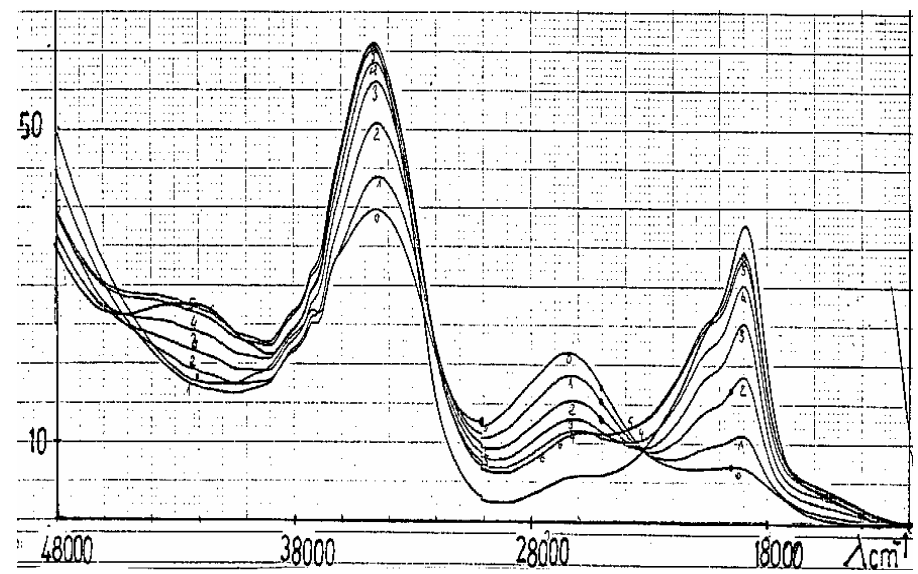

Figure 5. Absorbance measurement of $\mathrm{Ru}(\mathrm{hfacac})_{3}$ in propanol

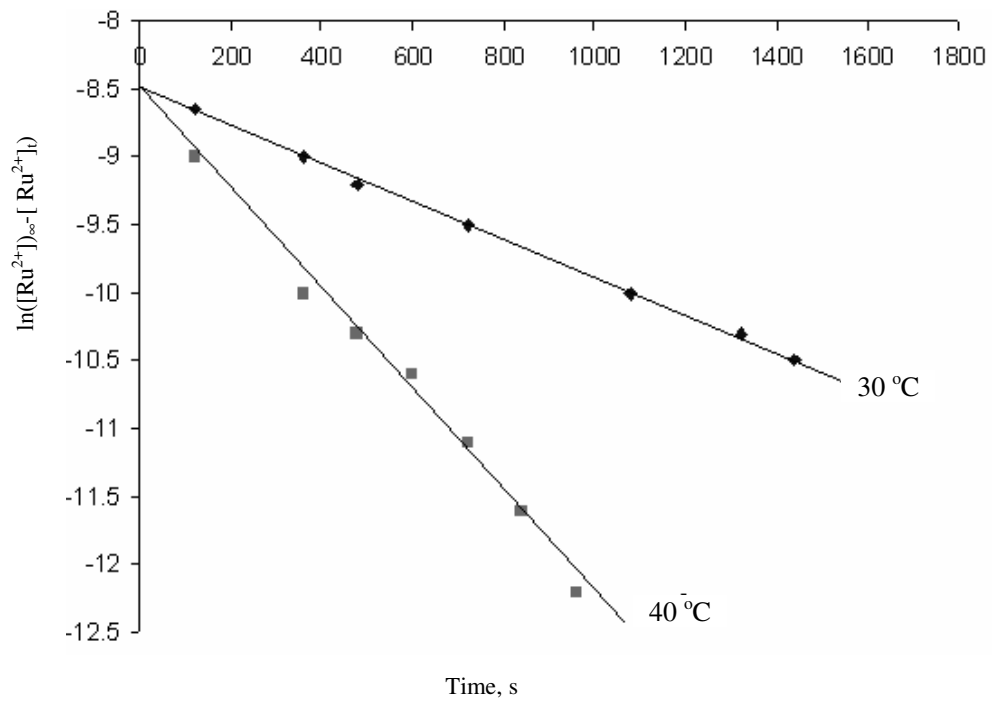

Figure 6. Rate measurement of $\mathrm{Ru}(\mathrm{hfacac})_{3}$ in propanolic $\mathrm{KOH}$ solution at 30 and $40{ }^{\circ} \mathrm{C}$ 
Table 3. Rate constants and half life for kinetic measurement in propanol

\begin{tabular}{cccc}
\hline Temperature, $\mathrm{K}$ & $\mathrm{K}, \mathrm{mole} / \mathrm{s} \times 10^{4}$ & $\operatorname{ln~} \mathrm{k}$ & $\mathrm{t}_{1 / 2}(\mathrm{~s})$ \\
\hline 298 & 1.05 & -9.16 & 6601.4 \\
303 & 1.417 & -8.86 & 4892.80 \\
313 & 3.55 & -7.94 & 1952.53 \\
323 & 13.7 & -6.595 & 507.18 \\
\hline
\end{tabular}

Activation parameters were then determined from the slope of the plot of $\ln \mathrm{k}$ versus $1 / \mathrm{T}$ over the temperature range of $15-50{ }^{\circ} \mathrm{C}$ for a number of representative reactions. The energies of activation obtained for methanol and ethanol indicate that the reduction is fastest in methanol Table 4.

Table 4. Measured thermodynamic properties

\begin{tabular}{cccccc}
\hline Alcohol & $\begin{array}{c}\text { Graphical } \\
\text { Evaluation of } \\
E_{a}, \mathrm{~kJ} / \mathrm{mol}\end{array}$ & $\begin{array}{c}\text { Least square } \\
\text { evaluation of } \\
E_{a}, \mathrm{~kJ} / \mathrm{mol}\end{array}$ & $\begin{array}{c}\text { Error of } \\
\text { slope, } \\
\mathrm{kJ} / \mathrm{mol}\end{array}$ & $\begin{array}{c}\text { Enthalpy of } \\
\text { Activation, } \\
\Delta H\end{array}$ & $\begin{array}{c}\text { Entropy of } \\
\text { Activation, } \\
\Delta S, \mathrm{~J} / \mathrm{mol}\end{array}$ \\
\hline Methanol & 85.34 & 85.41 & 1.00 & 82.86 & -42.15 \\
Ethanol & 108.1 & 103.9 & 0.202 & 101.446 & +22.95 \\
Propanol & 94.571 & 96.890 & 1.46 & 94.41 & -12.22 \\
\hline
\end{tabular}

Calculated entropies of activation for each of the alcohols gave negative values for methanol and propanol and signify a lack of induced dipole - dipole interaction and also show a separation of ions in the system. However, the positive entropy value for ethanol signifies the presence of dipole - dipole interaction.

Barley \& becker ${ }^{21}$ in their study of electron transfer dynamics have stated that solvents in many chemical reactions play a less passive role. In their measurement of a number of polar solvents found that dielectric relaxation time of polar fluids is a measure of the damping or reorientation of the dipole. Man sheung et al. ${ }^{14}$ studying electron exchange rate between $\mathrm{Ru}(\mathrm{hfacac})_{3}$ and $\mathrm{Ru}(\mathrm{hfacac})_{3}{ }^{-}$in different solvents have stated that the main deterrent to electron transfer is probably the necessity of solvent reorganization and that exchange reactions increase with decreasing values of the dielectric constant.

Indicates an electron transfer from alcohol to ruthenium reducing ruthenium(III) to ruthenium(II). The mode of electron transfer for this reaction process has been described by many researchers as an outer sphere process where the transfer of electron proceeds without opening of the chelate rings 5 .

\section{Conclusion}

Tris-(1,1,1,5,5,5-hexafluoroacetylacetonato) ruthenium(III) (Ru(hfacac) $\left.)_{3}\right)$ was synthesized by the ruthenium blue method with a slight modification as stated in the synthetic procedure. Kinetic reduction of $\left(\mathrm{Ru}(\mathrm{hfacac})_{3}\right)$ in various alcohols show a conversion to tris- $(1,1,1,5,5,5$ hexafluoroacetylacetonato) ruthenium(II) $\left(\mathrm{Ru}(\mathrm{hfacac})_{3}{ }^{-}\right)$. In methanol and ethanol the reduction reaction show a single set of reactants giving rise to a single set of products. The identity of the product have been reported by other researchers as ruthenium(II) ${ }^{12}$.

\section{References}

1. Combes A, Ann Chim Phys., 1887, 12, 245.

2. Endo A, Shimizu K, Sato G P and Mukaido M, Chem Letts., 1984, 437- 440.

3. Bruce M I, Coord Chem Rev., 1987, 76, 1- 43. 
4. Koiwa T, Masuda Y, Shono J, Kawamoto Y, Hoshino Y, Hashimoto T, Natarajan K and Shimizu K, Inorg Chem., 2004, 43(20), 6215-6223.

5. Trzeciak A M, Grobelny R and Ziołkowski J J, React Kinet Catal Lett., 1981, 17, 121- 125.

6. Trzeciak A M, Grobelny R, Maćkowiak A and Ziołkowski J J, Oxid Comm., 1984, 7, 283-293.

7. Morris M L and Koob R D, Inorg Chem., 1983, 22, 3502

8. Baird I R, Rettig S J, James B R and Skov K A, Can J Chem., 1999, 77(11), 1821- 1833.

9. Zhou J and Swaddle T W, Can J Chem., 2001, 79(5-6), 841-847.

10. Veening H, Bachman W E and Wilkinson D M J, Gas Chromatogr., 1967, 5, 248-250

11. Carol C, Peter K, Tadashi M, Netzel T L and, Sutin N, J Amer Chem Soc., 1979, 101(18), 5442-5444.

12. Grobelny R and Banaś B, React Kinet Catal Lett., 1984, 24, 217-222.

13. Takeuchi Y, Endo A, Shimizu K and Sato G P, J Electroanal Chem., 1985, 185, 185- 189.

14. Chan M S and Wahl A C, J Phy Chem., 1982, 86, 126 - 130.

15. Holm R H and Cotton F A, J Amer Chem Soc., 1958, 80, 5658

16. Collman J P and Yamada M, J Org Chem., 1963, 28, 3017.

17. Joshi K C and Pathak V N, Coord Chem Rev., 1977, 22, 37

18. Grobelny R, Trzebiatowska J and Wojciechowski W, J Inorg Nucl Chem., 1966, 28, 2715.

19. Seddon E A and Seddon K R, The Chemistry of Ruthenium, Elsevier, 1985, 113.

20. Barnum D W, J Inorg Nucl Chem., 1961, 21, 221-237

21. Barley M, Becker J Y, Domazetis G, Dolphin D and James B R, J Chem Soc Chem Comm., 1981, 982-983. 


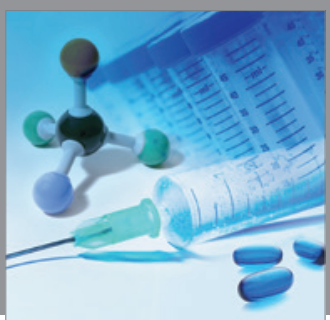

International Journal of

Medicinal Chemistry

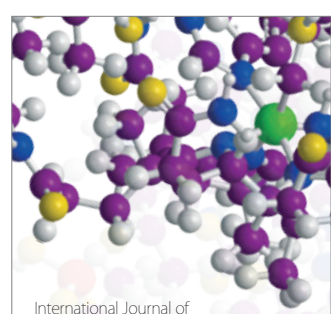

Carbohydrate Chemistry

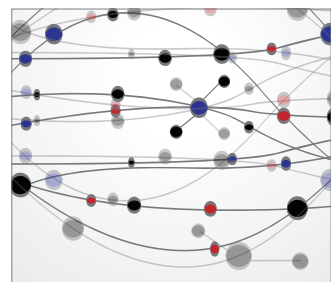

The Scientific World Journal
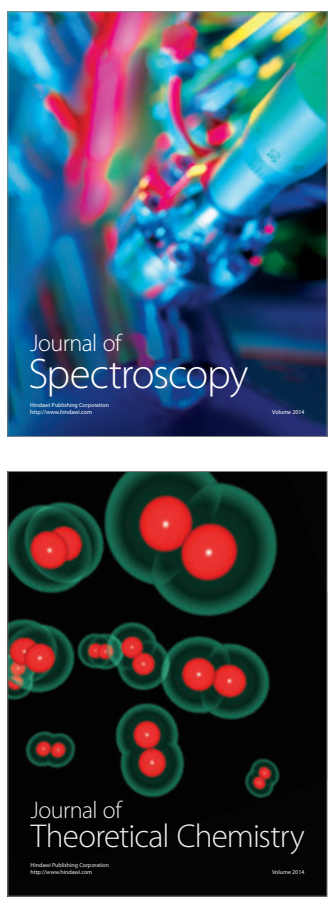
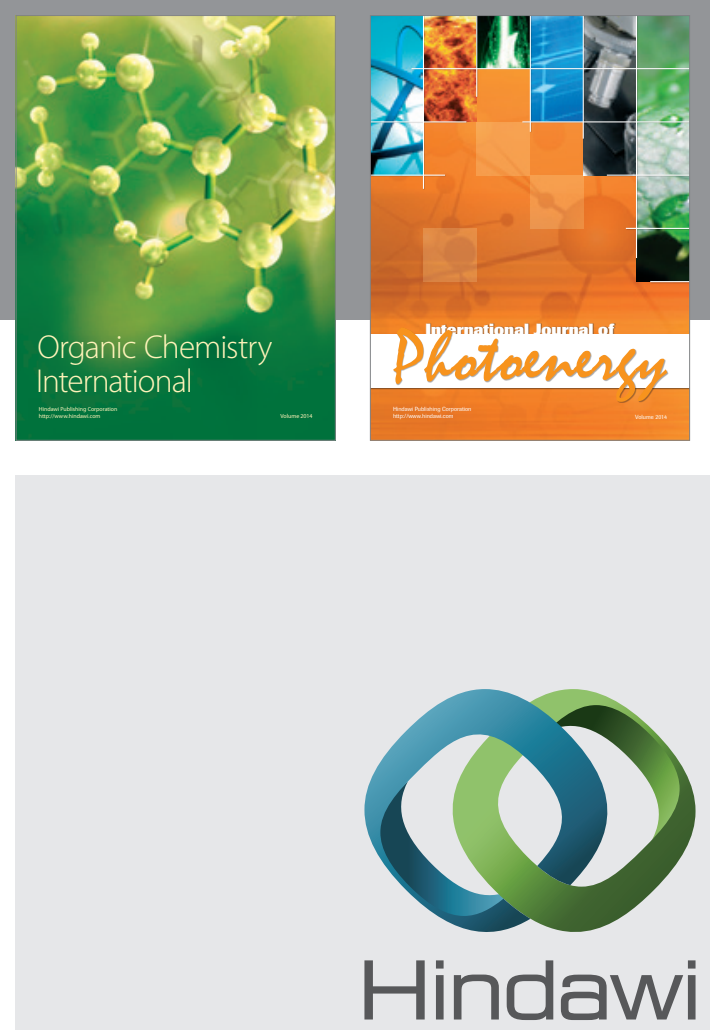

Submit your manuscripts at

http://www.hindawi.com
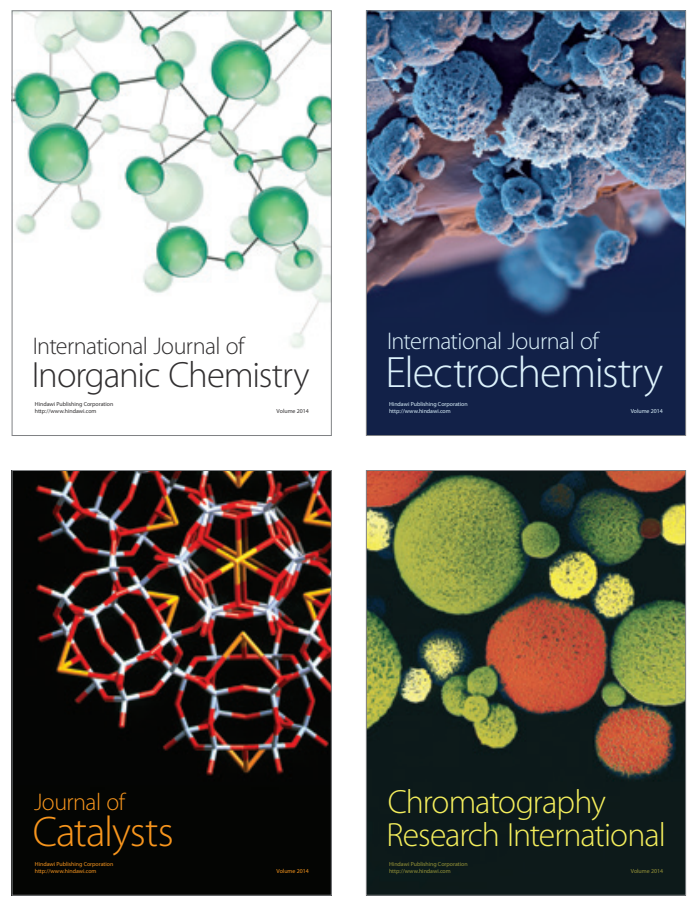
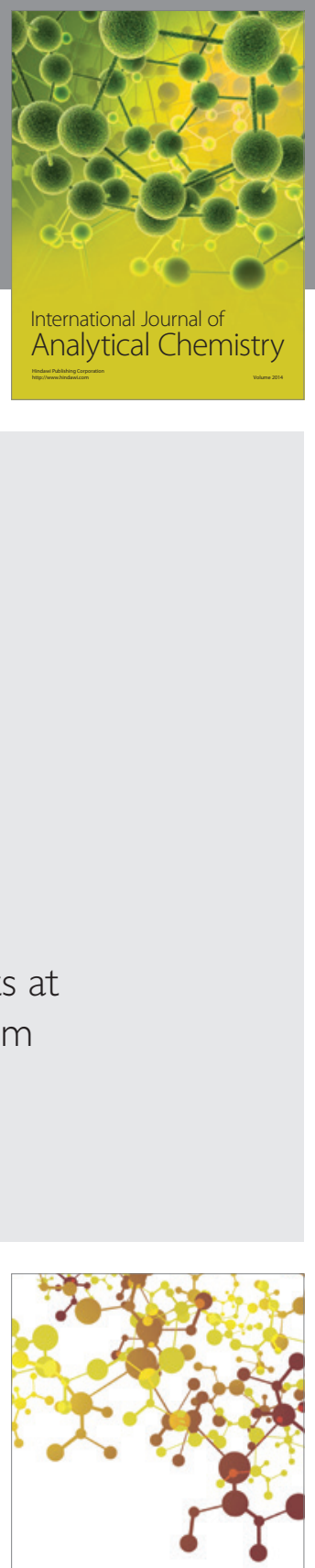

Journal of

Applied Chemistry
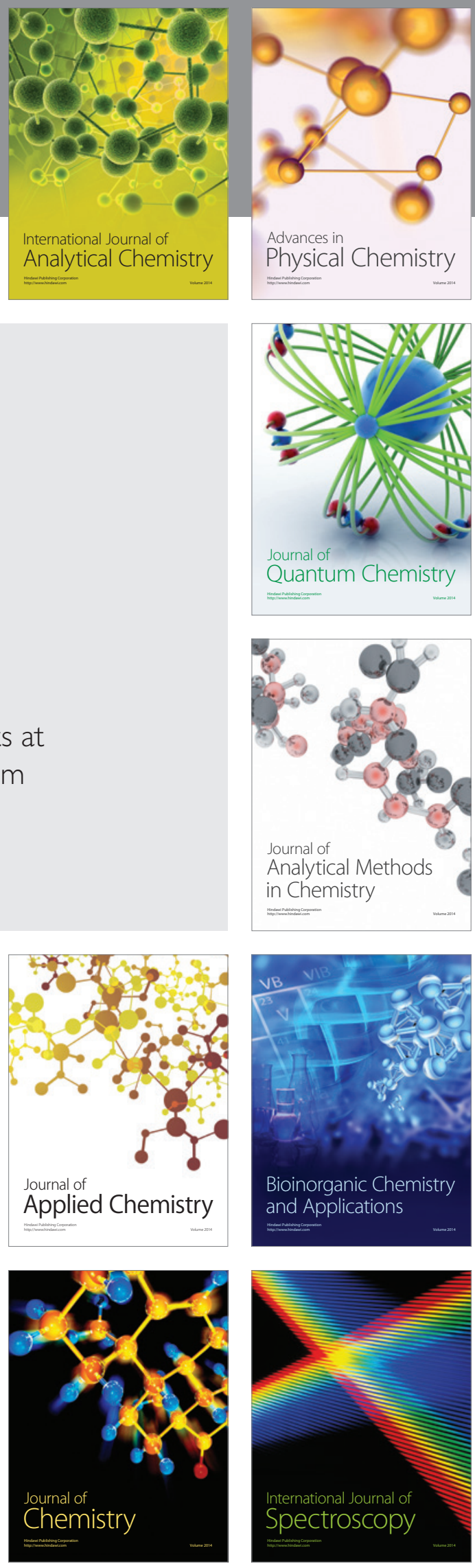